\title{
Psychometric evaluation of the PROMIS social function short forms in Chinese patients with breast cancer
}

\author{
Tingting Cai, Qingmei Huang, Fulei Wu and Changrong Yuan* (1)
}

\begin{abstract}
Background: The diagnosis of breast cancer and the subsequent treatment undermine patients' participation in social activities. This study aimed to carry out a cross-cultural adaption and analysis of the construct validity and reliability of the Chinese version of the PROMIS social function short forms in patients with breast cancer.

Methods: This study utilized a cross-sectional research design, and was registered in the Chinese Clinical Trial Registry (ChiCTR2000035439). After a standardized cross-cultural adaption process, a psychometric evaluation was performed of the Chinese version of the PROMIS social function short forms. Using convenience sampling, eligible patients with breast cancer from tertiary hospitals in China were enrolled from January 2019 to July 2020. Participants completed the sociodemographic information questionnaire, the PROMIS social function short forms, the Functional Assessment of Cancer Therapy-Breast, the PROMIS emotional support short form and the PROMIS anxiety short form.
\end{abstract}

Results: Data were collected from a sample of 633 patients whose mean age was 48.1 years. The measures showed an absence of floor and ceiling effects. Regarding construct validity, the results of confirmatory factor analysis supported the original two-factor structure of the PROMIS social function short forms. In addition, the measures were found to have acceptable known-group validity, measurement invariance, and convergent and discriminate validity. Regarding reliability, the Cronbach's a was high for all items ( $>0.70)$.

Conclusion: The Chinese version of the PROMIS social function short forms was demonstrated to be a valid and reliable measure for the assessment of social function in Chinese patients with breast cancer. Additional psychometric evaluation is needed to draw firm conclusions.

Keywords: Psychometric analysis, PROMIS, Social function, Breast cancer

\section{Background}

Currently, breast cancer is the most common cancer type in women worldwide [1]. Evidence indicates that a higher level of quality of life is related to greater social function $[2,3]$. The diagnosis of breast cancer and the subsequent treatment undermine patients' participation in social activities [4]. In addition, they entail the emergence or

*Correspondence: yuancr@fudan.edu.cn

School of Nursing, Fudan University, 305 Fenglin Road, Shanghai 200032, China worsening of social interaction problems between individuals and their surroundings, which not only affects the rehabilitation process but might also result in treatment interruptions [5]. Furthermore, reduced social participation may be detrimental to patients' health outcomes [6, 7]. To identify patients with social function issues caused by breast cancer, a measure accounting for the diversity and dynamic nature of social function is required [8].

Social function (or social participation) is conceived as an individual's involvement in and satisfaction with his or her usual roles in life situations and activities [9]. Social function issues in patients with breast cancer remain an original author(s) and the source, provide a link to the Creative Commons licence, and indicate if changes were made. The images or other third party material in this article are included in the article's Creative Commons licence, unless indicated otherwise in a credit line to the material. If material is not included in the article's Creative Commons licence and your intended use is not permitted by statutory regulation or exceeds the permitted use, you will need to obtain permission directly from the copyright holder. To view a copy of this licence, visit http://creativecommons.org/licenses/by/4.0/. The Creative Commons Public Domain Dedication waiver (http://creativeco mmons.org/publicdomain/zero/1.0/) applies to the data made available in this article, unless otherwise stated in a credit line to the data. 
underemphasized area in China, in part because few reliable and valid measures are currently available for incorporation into routine screening in breast cancer care [8]. Routine evaluation of social function that allows the assessment of objective participation performance and subjective satisfaction with participation is needed for patients with breast cancer.

Social function assessment is influenced by several factors, such as cultural factors in the evaluation context. Short and accurate self-report measures are needed to enable the identification of individuals with social function issues and to follow them up. The Patient-Reported Outcomes Measurement Information System (PROMIS) addresses this gap with a series of measures of social health. PROMIS measures contribute to the measurement of a wide range of symptoms, functioning, and well-being outcomes from the patient's perspective and represent a standardized scoring system with a rigorous and sound methodology covering the physical, mental, and social health domains [10-12]. Within the PROMIS framework, the PROMIS Social Health Workgroup developed measures to evaluate social function by engaging in a series of qualitative and quantitative efforts such as definition formulation, qualitative item reviews, focus groups, cognitive interviews and large-scale testing with a general population sample following standard PROMIS guidelines [9].

The PROMIS social function short forms are a promising alternative to existing instruments for evaluating social function [9]. The measures assess distinct but related aspects of social function and are self-reported measures using only a minimal number of items while maintaining precision [13]. The measures represent great progress in the brief yet accurate assessment of social function for repeated application in situations that require a quick and continuous follow-up assessment and allow for low-burden data capture. The PROMIS social function short forms have been utilized in different cultures and are demonstrated to have adequate psychometric properties in diverse clinical populations $[9,13]$.

The self-report nature and short valid response method of the PROMIS social function short forms suggest their potential for use as screening tools in the assessment of social function in patients with breast cancer [13]. Considering this, this study aimed to carry out a cross-cultural adaption and analysis of the psychometric properties of the Chinese version of the PROMIS social function short forms in patients with breast cancer.

\section{Methods Design}

This study utilized a cross-sectional research design, and was registered in the Chinese Clinical Trial Registry
(ChiCTR2000035439). Two phases were carried out, namely, translation and cognitive interviews, followed by a psychometric evaluation of the Chinese version of the PROMIS social function short forms. Figure 1 presents the flow of the standardized phases of the study.

\section{Phase I: translation and cognitive interviews}

The PROMIS Health Organization authorized our research group to translate the original English version of the PROMIS social function short forms into simplified Chinese. A standardized transcultural procedure was carried out by strictly following the Functional Assessment of Chronic Illness Therapy translation method (FACITtrans), which is an international guideline for translation procedures recommended by the PROMIS Statistical Center [14]. The translation involved multiple forward translations, reconciliation, back-translation, independent expert reviews, formatting, and proofreading following recommended guidelines. All the translators have a master's degree or above; one is a linguistics expert and two are Chinese-Canadian researchers who are native English speakers and have a good command of Chinese. First, two bilingual and bicultural translators from China and Canada independently completed two forward-translated versions of the measures into simplified Chinese. Both of these translators had a background in linguistics. Following this, a Chinese-speaking translator completed a reconciliation of the two versions. Back-translation was then performed by a native English translator who was proficient in Chinese. Subsequently, three native Chinese linguists and health experts were recruited to independently review all the versions to select the most appropriate one or to provide alternative translations for an optimal version. Finally, the translation project manager of our research group completed the formatting and proofreading work with the help of a language coordinator and two proofreaders to combine all previous versions and made necessary item modifications.

Therefore, the PROMIS social function short forms was determined by consensus. The measures were then validated in Chinese-speaking adults to compare the item equivalence between the Chinese version and the original English version. Participants were asked to report whether there were incomprehensible items and then provide a more appropriate expression. Five patients with breast cancer and five healthy adults were recruited for cognitive interviews on the items and the response options. The measures were further modified based on participants' feedback to make them more comprehensible and acceptable and were reviewed by the PROMIS Health Organization. The prefinal version 

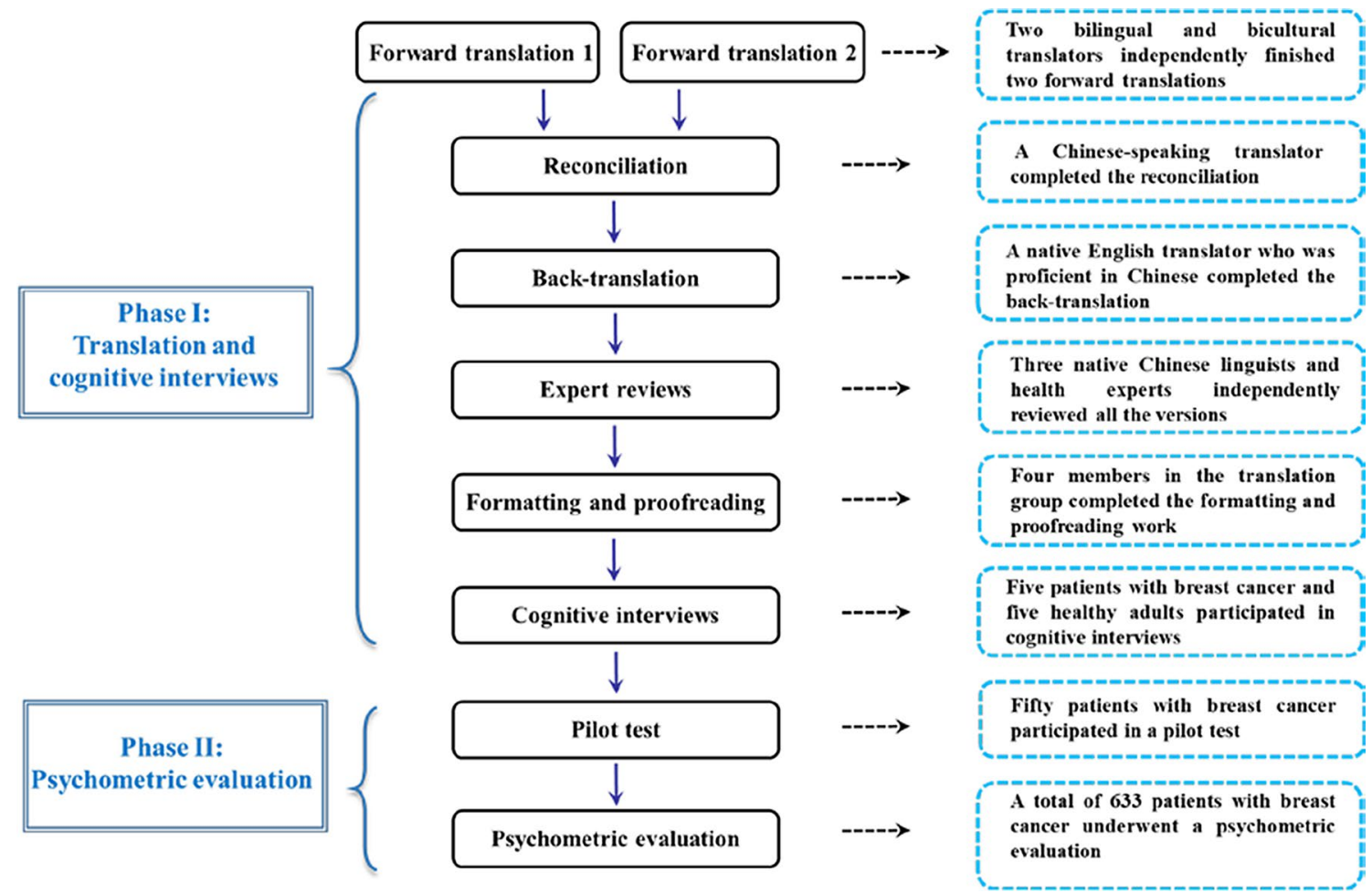

Fig. 1 Flow of the multiple standardized phases of the study

was pilot-tested in a sample of 50 Chinese patients with breast cancer and subsequently revised.

\section{Phase Il: psychometric evaluation}

Before widely applying the PROMIS social function short forms in clinical settings, a multicenter cross-sectional study was conducted to assess the psychometric properties in terms of construct validity and reliability following the practices recommended by Consensus-based standards for the selection of health measurement instruments (COSMIN).

\section{Setting and sample}

Using a convenience sampling method, participants from the breast care wards of tertiary hospitals in Shanghai Province were recruited from January 2019 to July 2020. The inclusion criteria for patients were as follows: (a) aged 18 or older, (b) had a diagnosis of stage I to IV breast cancer, (c) received medical treatment for breast cancer, (d) had an adequate understanding of Mandarin, and (e) signed an informed consent form. Patients with psychiatric illness, cognitive impairment or diagnosis of another cancer type were excluded. According to the recommendation of the PROMIS National Center, three to ten respondents should participate in cognitive interviews for each item [14]. Because there are eight items in the PROMIS social function short forms, we chose five patients with breast cancer and five healthy adults for cognitive interviews. Regarding the psychometric evaluation, the ratio of cases to variables was $>20: 1(633: 8)$ in this study, which is over the recommended rule of thumb value (5-10:1) [15]. The sample size was sufficient to perform stable and precise model estimation by confirmatory factor analysis (CFA) [15].

\section{Measures}

\section{Sociodemographic information questionnaire}

A sociodemographic information questionnaire was developed to collect sociodemographic and clinical data regarding age, marital status, childbearing history, religion, educational background, menstrual status, living style, employment status, monthly family income, health insurance, and medical treatment. Sociodemographic data were self-reported by the patients, while clinical data were obtained from their medical records by trained nurse researchers.

\section{PROMIS social function short forms}

The PROMIS social function short forms comprise two subscales, namely, the PROMIS Ability to Participate in Social Roles and Activities short form and the PROMIS Satisfaction with Social Roles and Activities short form, 
of varying lengths (4-, 6-, and 8-item short forms); they assess limitations and satisfaction with social function, respectively [16]. The PROMIS social function short forms in all three lengths have been reported to be highly reliable across mild to severe levels of clinical severity and sensitive to differences in self-reported social function [17]. Therefore, we selected the shortest version of the measures (4-item short forms) to reduce the burden on the respondents. The total raw score ranges from 8 to 40 , with high scores representing a high level of social participation or satisfaction with social participation. Subsequently, the scores were normalized according to a mean standardized T-score metric, with a mean of 50 and a standard deviation of 10 representing the average level of the general US population $[18,19]$.

\section{Functional assessment of cancer therapy-breast}

The Chinese version of the Functional Assessment of Cancer Therapy-Breast (FACT-B) is a 36-item multidimensional scale specifically designed to assess quality of life in the past 7 days in patients with breast cancer [20]. The FACT-B was used in the present study as an indirect measurement to explore the convergent validity of the PROMIS social function short forms. The scale comprises five subscales: physical, social/family, emotional, functional well-being, and the breast cancer-specific subscale [21]. Each item is evaluated on a 5-point Likert-type scale from 0 ("not at all") to 4 ("very much"). The overall score is the summary score of the subscales; the total score ranges from 0 to 144, and higher scores indicate better quality of life $[22,23]$. The Chinese version of the FACT-B has acceptable psychometric properties in Chinese patients with breast cancer [24, 25]. The Cronbach's $\alpha$ of the scale was 0.93 in this study.

\section{PROMIS emotional support short form}

The Chinese version of the 4-item PROMIS emotional support short form was utilized to explore the convergent validity of the PROMIS-social function short forms. The responses are scored within a seven-day recall period with a five-point Likert scale $(1=$ never, $2=$ rarely, $3=$ sometimes, $4=$ often, $5=$ always) [26]. The total raw score ranges from 8 to 40 , with higher scores indicating better emotional support [27]. The scores are reported as $\mathrm{T}$ scores (with a mean of 50 and a standard deviation of 10) [9]. The scale has been validated in Chinese patients with breast cancer [28]. The Cronbach's $\alpha$ of the scale was 0.92 in this study.

\section{PROMIS anxiety short form}

The Chinese version of the 8-item PROMIS anxiety short form was utilized to examine the discriminant validity in this study. The items use a 7-day time frame and a
5 -point rating scale $(1=$ never, $2=$ rarely, $3=$ sometimes, $4=$ often, and $5=$ always) [28]. The total score of the scale ranges from 8 to 40, with higher scores indicating greater anxiety [29]. Raw scores are transformed on a T metric (mean $=50, \mathrm{SD}=10$ ). The Cronbach's $\alpha$ of the scale was 0.93 in the current study.

\section{Procedures}

The ethics committee of the Institutional Review Boards of Fudan University Cancer Hospital (no 1810192-22) and Fudan University Zhongshan Hospital (no 2020076R) reviewed and approved this study. Eligible patients who met the inclusion criteria were invited to participate after a review of the medical records. The participants gave their voluntary consent to be involved with the help of their nurses during hospitalization. Data were collected by trained nurse researchers at each study site. All the participants were informed about the purpose and procedures of the study. In addition, participants were informed of the voluntary nature of participation, participants' rights, and the confidentiality of the data. All participants gave formal written consent to participate. Participants could choose to complete the survey either on paper or using web-based questionnaires based on their preferences. The participants were required to return the questionnaire immediately after completion. Consenting participants completed the sociodemographic information questionnaire, the PROMIS social function short forms, the Functional Assessment of Cancer Therapy-Breast, the PROMIS emotional support short form and the PROMIS anxiety short form. Data were checked for random responding.

\section{Statistical analysis}

The statistical analyses were performed with IBM SPSS version 21.0 and AMOS version 23.0. Descriptive statistics were calculated for the sociodemographic data and to determine the distribution of items. A floor effect refers to the proportion of patients with the lowest raw scores, whereas a ceiling effect refers to the proportion of patients with the highest raw scores, with a proportion greater than $15 \%$ being considered indicative of a floor or ceiling effect [30].

The construct validity of the measures was examined. Two constructs, limitations and satisfaction with social function, were supposed to be found according to the conceptual framework developed by the authors of the PROMIS social function short forms [16]. CFA was performed to identify the underlying factor structure of the Chinese version of the PROMIS social function short forms, and a CFA model with a two-factor structure was expected to be supported. The measures were treated as ordered categorical variables in the CFA analysis. To 
examine the goodness of model fit, indices including the $x^{2} /$ degree of freedom $\left(x^{2} / d f\right)$, goodness-of-fit index (GFI), comparative fit index (CFI), Tucker-Lewis index (TLI), incremental fit index (IFI), and root mean square error of approximation (RMSEA) were included. An acceptable CFA model should have a $\chi^{2} / \mathrm{df}<3$; a GFI, CFI, TLI and IFI > 0.9; and a RMSEA $<0.08$ [31, 32]. Items with a factor loading equal to or higher than the criterion of 0.4 were retained [33].

Considering the results of previous studies, the social function of patients with breast cancer was expected to differ significantly by employment status $[34,35]$. Therefore, known-group validity was evaluated by comparing $\mathrm{T}$-scores between patients reporting different employment statuses using the analysis of variance.

To test whether the measures provided biased results across different populations, differential item functioning (DIF) was examined for each item in the PROMIS social function short forms. DIF analyses were performed to test the measurement invariance and identify whether patients with the same trait from different groups have different probabilities of giving certain response to items [36]. Items with significant DIF indicate measurement bias [36]. Therefore, measurement invariance was evaluated by considering DIF of the PROMIS social function short forms due to age and education.

Convergent and discriminant validity were examined by testing the correlations between similar and dissimilar traits. Pearson correlation coefficients were utilized in this study, with values of $0-0.30$ representing negligible correlation; $0.30-0.50$ indicating weak correlation; $0.50-$ 0.70 indicating moderately strong correlation and above 0.70 indicating strong correlation [37]. Convergent validity is supported when the scores of measures in a similar domain are correlated, but not so strongly as to be redundant ( $\mathrm{r}$ between 0.40 and 0.80) [38]. Discriminant validity is established when correlations between scores of different traits are low $(\mathrm{r}<0.30)$ [38]. We hypothesized that the social function level of patients with breast cancer would be positively correlated with their degree of quality of life and emotional support. Therefore, it was hypothesized that the correlations between the scores of the PROMIS social function short forms and those of the Functional Assessment of Cancer Therapy-Breast and the PROMIS emotional support short form would be significant since all these measures focus on social health. Conversely, the correlations between the PROMIS social function short forms score and the PROMIS anxiety short form score should be negligible since the measures are of dissimilar constructs.

The reliability of the measures was evaluated by Cronbach's $\alpha$ coefficient, split-half reliability, and item-tototal correlations. Minimally acceptable reliability was specified as greater than $0.70[39,40]$. For all statistical analyses, a probability of 0.05 was used to indicate statistical significance.

\section{Results \\ Descriptive statistics}

A total of 750 questionnaires were distributed. Ninetynine eligible patients did not consent to participate, while 651 agreed to be involved. The major reason for refusal was being overwhelmed with their cancer treatment or their family members not agreeing with their participation. In addition, 18 questionnaires were excluded for being incomplete. The final data were obtained from 582 paper questionnaires and 51 web-based questionnaires. Therefore, psychometric analysis of the PROMIS social function short forms was performed with a sample of 633 participants. The average age of the respondents was 48.1 years, with a range of $23-76$ years $(S D=9.97)$. Most respondents reported that they were married (94.16\%), had a childbearing history (98.39\%), were premenopausal (52.76\%), had no religion (92.10\%), finished secondary school (31.75\%), lived with family $(94.15 \%)$, were unemployed (45.82\%), had a monthly family income of less than $¥ 3000 / \$ 450(52.61 \%)$, had employee health insurance $(53.87 \%)$, and underwent chemotherapy (92.58\%) (Table 1).

Table 2 provides an overview of the proportion of respondents who achieved the lowest or highest raw scores for each item. No floor or ceiling effects were found for the PROMIS social function short forms (Table 3). We transformed theta scores into T scores. The average $\mathrm{T}$ scores for the PROMIS Ability to Participate in Social Roles and Activities short form and the PROMIS Satisfaction with Social Roles and Activities short form were $51.49 \pm 9.86$ and $50.36 \pm 9.92$, respectively; both scores are average.

\section{Construct validity}

We examined the two-factor solution of the CFA. All factor loadings in the two-factor CFA model of the 8 items were above the standard of 0.4 (Fig. 2). The goodness of fit of the two-factor model was acceptable: $\chi^{2} / \mathrm{df}=2.133$, $P<0.001, \quad$ RMSEA $=0.052, \quad$ GFI $=0.931, \quad$ CFI $=0.939$, $\mathrm{TLI}=0.910$, and IFI $=0.923$. In addition, there were positive correlations between the two constructs of social function $(P<0.05)$. The variable loadings on limitation of social function ranged from 0.75 to 0.84 ; the loadings on satisfaction with social function ranged from 0.67 to 0.81 . The results supported a two-factor structure of the Chinese version of the PROMIS social function short forms in patients with breast cancer.

To examine the known-group validity of the PROMIS social function short forms, the scores were compared 
Table 1 Demographic and clinical characteristics of the study sample $(\mathrm{N}=633)$

\begin{tabular}{|c|c|}
\hline Variables & Frequency (Percent) \\
\hline Age (Mean \pm SD) & $48.07 \pm 9.97$ \\
\hline \multicolumn{2}{|l|}{ Marital status } \\
\hline Single & $13(2.05)$ \\
\hline Married & $596(94.16)$ \\
\hline Divorced & $14(2.21)$ \\
\hline Widowed & $10(1.58)$ \\
\hline \multicolumn{2}{|l|}{ Childbearing history } \\
\hline Yes & $615(98.39)$ \\
\hline No & $18(1.61)$ \\
\hline \multicolumn{2}{|l|}{ Menstrual status } \\
\hline Premenopausal & $334(52.76)$ \\
\hline Postmenopausal & $299(47.24)$ \\
\hline \multicolumn{2}{|l|}{ Religion } \\
\hline Yes & $50(7.90)$ \\
\hline No & $583(92.10)$ \\
\hline \multicolumn{2}{|l|}{ Education background } \\
\hline Primary school or below & $157(24.80)$ \\
\hline Secondary school & $201(31.75)$ \\
\hline High school & $129(20.38)$ \\
\hline University or above & $146(23.07)$ \\
\hline \multicolumn{2}{|l|}{ Lifestyle } \\
\hline Living alone & $18(2.84)$ \\
\hline Living with family & $596(94.15)$ \\
\hline Living with others & $19(3.01)$ \\
\hline \multicolumn{2}{|l|}{ Current employment } \\
\hline Employed & $92(14.53)$ \\
\hline Medical leave & $132(20.85)$ \\
\hline Unemployed & $290(45.82)$ \\
\hline Retired & $119(18.80)$ \\
\hline \multicolumn{2}{|l|}{ Monthly family income } \\
\hline$\leq ¥ 3000(\$ 450)$ & $333(52.61)$ \\
\hline$¥ 3000-¥ 9000(\$ 450-\$ 900)$ & $274(43.29)$ \\
\hline$>¥ 9000(\$ 900)$ & $26(4.10)$ \\
\hline \multicolumn{2}{|l|}{ Medical insurance } \\
\hline Free medical insurance & $4(0.63)$ \\
\hline Employee health insurance & $341(53.87)$ \\
\hline Rural health insurance & $257(40.60)$ \\
\hline Without health insurance & $31(4.90)$ \\
\hline \multicolumn{2}{|l|}{ Medical treatment } \\
\hline Postoperative stage & $6(0.95)$ \\
\hline Chemotherapy & $586(92.58)$ \\
\hline Radiotherapy & $17(2.69)$ \\
\hline Targeted therapy & $8(1.26)$ \\
\hline Endocrine therapy & $2(0.32)$ \\
\hline Combination of therapies & $14(2.20)$ \\
\hline
\end{tabular}

across patients with different employment statuses. The results provided evidence that social function scores were significantly different in employed and unemployed patients with breast cancer, with employed individuals reporting higher scores than those who were unemployed, indicating acceptable known-group validity (Table 4).

Measurement invariance was evaluated by examining DIF. Specifically, patients of different ages (18-39 years, 40-59 years, and $\geq 60$ years) and educational backgrounds (primary school or below, secondary school, high school, and university or above) were compared to identify whether there was DIF in the items. No significant DIF was found for any item, which showed that the measures were invariant across patients with different sociodemographic characteristics (Table 5).

Regarding convergent validity and discriminant validity, in accordance with our hypotheses, the PROMIS social function short forms presented a significant correlation with the PROMIS emotional support short form and the Functional Assessment of Cancer TherapyBreast. On the other hand, negligible correlations were found between the scores of the PROMIS social function short forms and the PROMIS anxiety short form. Therefore, the results indicated that higher scores on the PROMIS social function short forms were related to higher emotional support and quality of life scores but not significantly correlated with anxiety scores. The largest correlation was between the scores of the PROMIS Ability to Participate in Social Roles and Activities and PROMIS emotional support short form $(\mathrm{r}=0.54$, $P<0.05)$, which was a moderately strong correlation. The weakest correlation emerged between the scores of the PROMIS Ability to Participate in Social Roles and Activities and the PROMIS anxiety short form $(\mathrm{r}=0.08$, $P<0.05$ ), suggesting a negligible correlation (Table 6).

\section{Reliability analysis}

Regarding the reliability analysis, the internal consistency coefficients, Guttman split-half coefficient, and item-tototal correlations were calculated. The Cronbach's $\alpha$ values and split-half coefficients of the PROMIS Ability to Participate in Social Roles and Activities short form and the PROMIS Satisfaction with Social Roles and Activities short form were above the standard of 0.70 . In addition, the item-total correlations also indicated the acceptable reliability of the measures (Table 7).

\section{Discussion}

To the best of our knowledge, this study represents the first application of the PROMIS social function short forms in the Chinese cancer context. Following the PROMIS guidelines, a rigorous approach was used to 
Table 2 Item-level descriptive analysis

\begin{tabular}{|c|c|c|c|c|c|c|c|c|}
\hline \multirow[t]{2}{*}{ Item } & \multirow[t]{2}{*}{ Mean } & \multirow[t]{2}{*}{ SD } & \multicolumn{2}{|c|}{ Response of "1" } & \multicolumn{2}{|c|}{ Response of " 5 " } & \multirow[t]{2}{*}{ Skewness } & \multirow[t]{2}{*}{ Kurtosis } \\
\hline & & & $\mathbf{n}$ & $\%$ & $\mathbf{n}$ & $\%$ & & \\
\hline Ability to participate in social roles and activities 01 & 2.95 & 0.90 & 41 & 6.48 & 35 & 5.53 & 0.01 & 0.48 \\
\hline Ability to participate in social roles and activities 02 & 2.89 & 0.93 & 43 & 6.79 & 36 & 5.69 & 0.14 & 0.19 \\
\hline Ability to participate in social roles and activities 03 & 2.94 & 0.92 & 41 & 6.48 & 35 & 5.53 & 0.04 & 0.20 \\
\hline Ability to participate in social roles and activities 04 & 2.95 & 0.90 & 41 & 6.48 & 30 & 4.74 & -0.44 & 0.37 \\
\hline PROMIS satisfaction with social roles and activities 01 & 3.15 & 1.05 & 35 & 5.53 & 63 & 10.00 & -0.06 & -0.45 \\
\hline PROMIS satisfaction with social roles and activities 02 & 3.19 & 1.01 & 26 & 4.11 & 62 & 9.80 & -0.04 & -0.49 \\
\hline PROMIS satisfaction with social roles and activities 03 & 3.21 & 1.03 & 34 & 5.37 & 63 & 10.00 & -0.18 & -0.44 \\
\hline PROMIS satisfaction with social roles and activities 04 & 3.18 & 1.03 & 31 & 4.90 & 65 & 10.27 & -0.13 & 0.47 \\
\hline
\end{tabular}

Table 3 Floor and ceiling effects of the PROMIS social function short forms

\begin{tabular}{llc}
\hline Short form & Floor, N (\%) & Ceiling, N (\%) \\
\hline $\begin{array}{l}\text { PROMIS ability to participate in } \\
\text { social roles and activities short }\end{array}$ & $26(4.11)$ & $23(3.63)$ \\
$\quad$ form (raw sum score) & & \\
$\begin{array}{l}\text { PROMIS satisfaction with social } \\
\text { roles and activities short form } \\
\text { (raw sum score) }\end{array}$ & $18(2.84)$ & $46(7.27)$ \\
\hline
\end{tabular}

translate the original English version of the PROMIS social function short forms into a validated and culturally sensitive simplified Chinese version. Subsequently, we performed a cross-cultural adaption and psychometric testing of the PROMIS social function short forms in Chinese patients with breast cancer. The findings demonstrated the potential of the measures to reduce patient burden in addition to providing adequate reliability and construct validity in patients with breast cancer.

Regarding reliability, all items were above the minimal acceptable criterion of 0.70 , comparable with the original English version and suggesting acceptable reliability of the measures $[19,41]$. Although no floor or ceiling effects were found, the floor effects in this study $(4.11 \%, 2.84 \%)$ were higher than those reported by Carlozzi et al. (1.30\%, $1.30 \%)$ [41]. Additionally, the ceiling effects $(13.50 \%$, $12.70 \%)$ were higher than those found by Carlozzi et al. (3.63\%, 7.27\%). The average $\mathrm{T}$ scores for the PROMIS Ability to Participate in Social Roles and Activities short form and the PROMIS Satisfaction with Social Roles and Activities short form were $51.49 \pm 9.86$ and $50.36 \pm 9.92$, respectively, higher than the scores reported by Carlozzi et al. (49.80 \pm 8.60 and $47.80 \pm 8.30)$ [41]. Therefore, compared to the patients with traumatic brain injury investigated by Carlozzi et al. [41], patients with breast cancer might have better social function.
The results of CFA supported the original two-factor structure of the PROMIS social function short forms, consistent with the theoretically expected domains of limitation of and satisfaction with social function [16, 18]. The positive effect of employment status for patients with breast cancer has been proven in recent studies, in which work adjustments were a protective factor for occupational rehabilitation after the cancer diagnosis [42-44]. Consistent with our hypotheses, the PROMIS social functions short forms performed well in differentiating patients with different employment statuses, since employed patients reported better social function than unemployed individuals. The PROMIS measures are expected to use items without measurement bias across individuals who differ in terms of gender, age, and education [18]. Male breast cancer is a rare disease with an incidence of approximately $1 \%$ in China [45]. We failed to recruit male patients with breast cancer in this study. Since all participants in this study were women, we explored DIF only for the items regarding education and age. In accordance with the Dutch version of the PROMIS social functions short forms, patients with different ages and education levels interpreted the meaning of the items in a similar way, and the score differences were not due to group differences but to actual differences in social function, supporting the use of the measures in Chinese patients with breast cancer.

The convergent validity was supported by the strong correlations between the PROMIS social function short forms and measures of similar constructs. On the other hand, discriminant validity was confirmed by negligible correlations between the social function measures and measures of dissimilar constructs. The Functional Assessment of Cancer Therapy-Breast is a quality-oflife measure rather than a social health measure. Therefore, we hypothesized that the PROMIS Social functions short forms scores would correlate strongly $(r>0.50)$ with the PROMIS emotional support short form than 


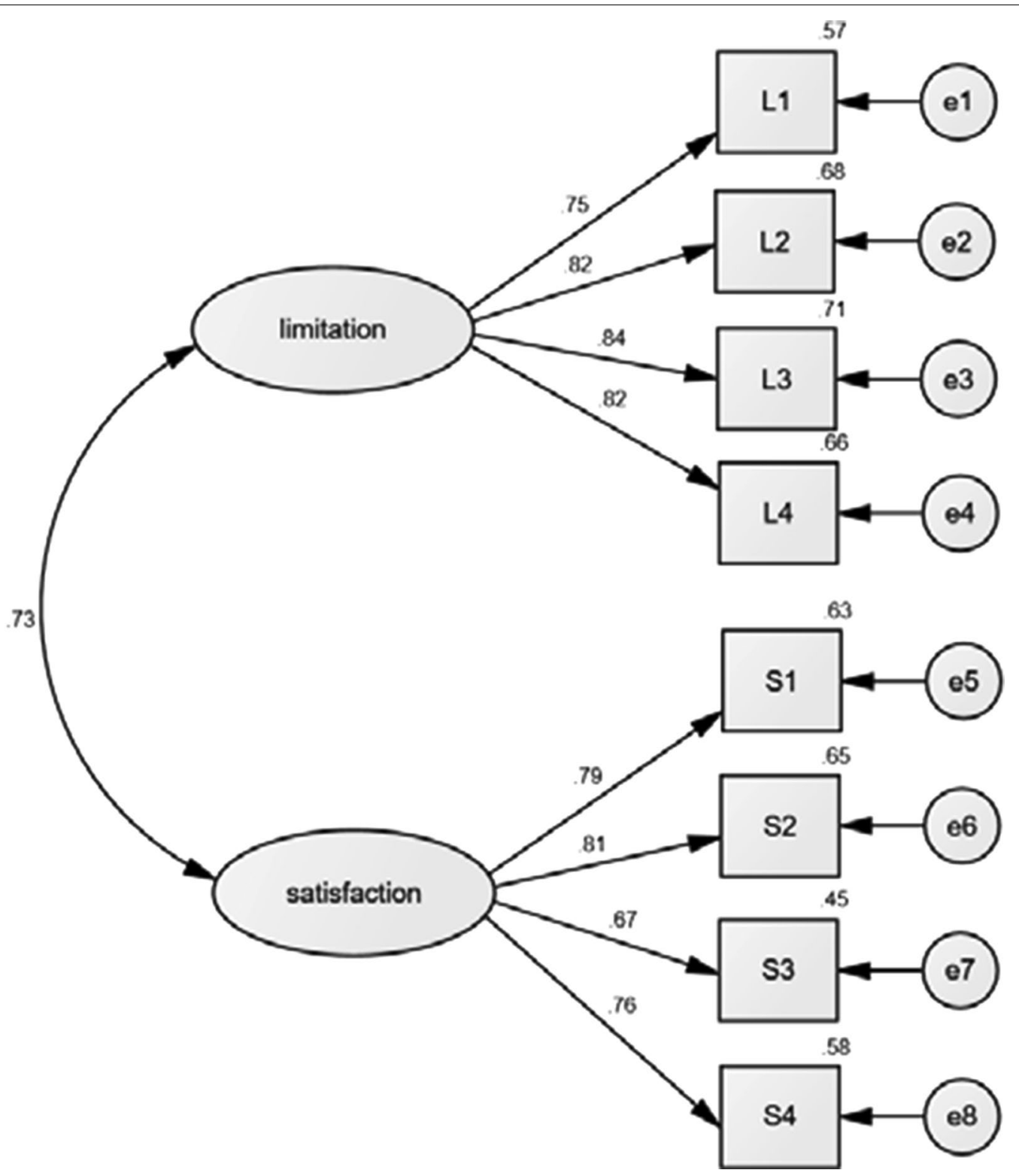

Fig. 2 Confirmatory factor analysis model of the PROMIS social function short forms

Table 4 Known-group validity of the PROMIS social function short forms

\begin{tabular}{|c|c|c|c|c|}
\hline \multirow[t]{2}{*}{ Known groups } & \multicolumn{2}{|c|}{$\begin{array}{l}\text { PROMIS ability to } \\
\text { participate in social } \\
\text { roles and activities }\end{array}$} & \multicolumn{2}{|c|}{$\begin{array}{l}\text { PROMIS satisfaction } \\
\text { with social roles and } \\
\text { activities }\end{array}$} \\
\hline & Mean (SD) & $P$ & Mean (SD) & $P$ \\
\hline Employed & $49.67(12.20)$ & & $51.91(12.14)$ & \\
\hline Unemployed & $50.35(8.14)$ & $<0.001$ & $48.99(9.18)$ & $<0.001$ \\
\hline
\end{tabular}

the Functional Assessment of Cancer Therapy-Breast. The measures were expected to be negligibly correlated with the PROMIS anxiety short form. The correlation results indicated that the greater the social function was, the greater the level of emotional support and quality of life, suggesting that the PROMIS social function short forms were compatible with social health-related measures but had low correlations with dissimilar measures. The findings were in line with a previous study showing the strong correlations of both the English and Spanish versions of the PROMIS social function short forms with social health-related measures such as the Functional 
Table 5 Differential item functioning parameter estimates for the PROMIS social function short forms

\begin{tabular}{lll}
\hline Items & DIF test $\boldsymbol{P}$ value & Education group \\
\cline { 2 - 3 } & Age group & 0.796 \\
\hline Ability to participate in social roles and activities 01 & 0.466 & 0.851 \\
Ability to participate in social roles and activities 02 & 0.941 & 0.813 \\
Ability to participate in social roles and activities 03 & 0.703 & 0.952 \\
Ability to participate in social roles and activities 04 & 0.732 & 0.125 \\
Satisfaction with social roles and activities 01 & 0.223 & 0.099 \\
Satisfaction with social roles and activities 02 & 0.075 & 0.289 \\
Satisfaction with social roles and activities 03 & 0.122 & 0.070 \\
Satisfaction with social roles and activities 04 & 0.088 & \\
\hline
\end{tabular}

Table 6 Convergent validity and discriminant validity of the PROMIS social function short forms

\begin{tabular}{|c|c|c|c|c|c|c|c|}
\hline \multirow[t]{2}{*}{ Short form } & \multicolumn{2}{|c|}{$\begin{array}{l}\text { PROMIS emotional support short } \\
\text { form }\end{array}$} & \multicolumn{3}{|c|}{ Functional assessment of cancer therapy-breast } & \multicolumn{2}{|c|}{$\begin{array}{l}\text { PROMIS anxiety } \\
\text { short form }\end{array}$} \\
\hline & $r$ & $P$ & $r$ & $P$ & & $r$ & $P$ \\
\hline $\begin{array}{l}\text { PROMIS ability to participate } \\
\text { in social roles and activities }\end{array}$ & 0.54 & $<0.001$ & 0.359 & $<0.001$ & 0.08 & & 0.045 \\
\hline $\begin{array}{l}\text { PROMIS satisfaction with } \\
\text { social roles and activities }\end{array}$ & 0.48 & $<0.001$ & 0.317 & $<0.001$ & -0.19 & & $<0.001$ \\
\hline
\end{tabular}

Table 7 Reliability of the PROMIS social function short forms

\begin{tabular}{llll}
\hline Short form & Cronbach's a & $\begin{array}{l}\text { Split-half } \\
\text { coefficient }\end{array}$ & $\begin{array}{l}\text { Item-total } \\
\text { correlations }\end{array}$ \\
\hline $\begin{array}{l}\text { PROMIS ability to partici- } \\
\text { pate in social roles and } \\
\text { activities short form }\end{array}$ & 0.88 & 0.85 & $0.68-0.75$ \\
$\begin{array}{l}\text { PROMIS satisfaction with } \\
\text { social roles and activi- } \\
\text { ties short form }\end{array}$ & & \\
\hline
\end{tabular}

Assessment of Cancer Therapy-General and the MOS 36-item Short Form Health Survey [27].

Given the results, the PROMIS social function short forms were acceptable for the clinical assessment of social function in patients with breast cancer. Having social function measures with sufficient psychometric properties is an important step for healthcare professionals to identify patients' social function issues and implement targeted interventions. Future studies are advisable to evaluate how the measures work in Chinese patients with other cancer types.

\section{Limitations}

This study has several limitations. First, our study is limited in its generalizability due to the convenience sampling of patients with breast cancer from tertiary hospitals. Only female patients were enrolled due to the very low incidence of male patients with breast cancer in China. Failure to recruit male patients is one of the limitations of this study. The sample may therefore not be representative of the total population of Chinese patients with breast cancer. In addition, data on testretest reliability, responsiveness evaluations and validity of reference assessments for hypothesis testing are warranted to further examine the psychometric properties of the measures.

\section{Conclusion}

This study indicates that the Chinese version of the PROMIS social function short forms has acceptable reliability and construct validity in patients with breast cancer. Further psychometric evaluation of some domains is warranted to draw firm conclusions.

\section{Acknowledgements}

The authors wish to extend our sincere thanks to the PROMIS network for allowing us to translate the original PROMIS social function short forms. The contributions made by the study sites enabled us to recruit the patients needed for our study.

\section{Authors' contributions}

All authors have contributed significantly to the design, analysis and writing of this manuscript. TC analyzed and interpreted the data, performed the original draft preparation, and completed the final submission. QH contributed to data collection and data analysis. FW translated the measures into simplified Chinese. CY made substantial contributions to conception and design, critical revision of manuscript for important content and gave final approval of the final draft. All authors read and approved the manuscript. 


\section{Funding}

This research was supported by the National Natural Science Foundation of China (Grant No. 71874032) and the Humanity and Social Science Youth Foundation of Ministry of Education (Grant No. 20YJCZH049). The funding provided assistance in the questionnaire collection process and the language editing service of the manuscript.

\section{Availability of data and materials}

All data presented in this paper are available from the corresponding authors on reasonable request.

\section{Declarations}

\section{Ethics approval and consent to participate}

The ethics committee of the Institutional Review Boards of Fudan University Cancer Hospital (no 1810192-22) and Fudan University Zhongshan Hospital (no 2020-076R) reviewed and approved this study. All participants gave formal written consent to participate.

\section{Consent for publication}

Not applicable.

\section{Competing interests}

The authors declare that they have no competing interests.

Received: 12 November 2020 Accepted: 11 May 2021

Published online: 18 May 2021

\section{References}

1. Ferlay J, Soerjomataram I, Dikshit R, Eser S, Mathers C, Rebelo M, et al. Cancer incidence and mortality worldwide: sources, methods and major patterns in GLOBOCAN 2012. Int J Cancer. 2015;136(5):359-86.

2. Lamprecht J, Thyrolf A, Mau W. The influence of social relationships on the quality of life of women with breast cancer. Phys Med Rehab Kuror. 2014;24(05):256-61.

3. Wondimagegnehu A, Abebe W, Abraha A, Teferra S. Depression and social support among breast cancer patients in Addis Ababa, Ethiopia. BMC Cancer. 2019;19:836.

4. Noreau L, Fougeyrollas P, Vincent C. The LIFE-H: assessment of the quality of social participation. Technol Disabil. 2002;14(3):113-8.

5. Sørensen HL, Schjølberg TK, Småstuen MC, Utne I. Social support in early-stage breast cancer patients with fatigue. BMC Women's Health. 2020;20:243.

6. Eyssen IC, Steultjens MP, Dekker J, Terwee CB. A systematic review of instruments assessing participation: challenges in defining participation. Arch Phys Med Rehab. 2011;92(6):983-97.

7. Douglas H, Georgiou A, Westbrook J. Social participation as an indicator of successful aging: an overview of concepts and their associations with health. Aust Health Rev. 2017;41(4):455-62.

8. Lv LM, Zhang XH, Wang XW, Zhang JL. A study on subthreshold depression and social participation among young and middle-aged patients after breast cancer surgery. J Nurs Sci. 2017;32(6):84-7.

9. Bode RK, Hahn EA, DeVellis R, Cella D. Measuring participation: the patient-reported outcomes measurement information system experience. Arch Phys Med Rehab. 2010;91(9):S60-5.

10. Cella D, Riley W, Stone A, Rothrock N, Reeve B, Yount S, et al. The patientreported outcomes measurement information system (PROMIS) developed and tested its first wave of adult self-reported health outcome item banks: 2005-2008. J Clin Epidemiol. 2010;63(11):1179-94.

11. Ahmed S, Berzon RA, Revicki DA, Lenderking WR, Moinpour CM, Basch $E$, et al. The use of patient-reported outcomes (PRO) within comparative effectiveness research. Med Care. 2012;50(12):1060-70.

12. Eremenco SL, Cella D, Arnold BJ. A comprehensive method for the translation and cross-cultural validation of health status questionnaires. Eval Health Prof. 2005;28(2):212-32.

13. Hahn EA, Beaumont JL, Pilkonis PA, Garcia SF, Magasi S, DeWalt DA, et al. The PROMIS satisfaction with social participation measures demonstrated responsiveness in diverse clinical populations. J Clin Epidemiol. 2016;73:135-41.

14. Kaat AJ, Schalet BD, Rutsohn J, Jensen RE, Cella D. Physical function metric over measure: an illustration with the patient-reported outcomes measurement information system (PROMIS) and the functional assessment of cancer therapy (FACT). Cancer. 2017;124(1):153-60.

15. Tinsley HEA, Tinsley DJ. Uses of factor analysis in counseling psychology research. J Couns Psychol. 1987;34(4):414-24.

16. Silva MCL, Mendonça TMS, Silva CHM, Pinto RMC. Cross-cultural adaptation to Portuguese of a measure of satisfaction with participation of the patient-reported outcomes measurement information system (PROMIS(r)). Trends Psychiatry Psychother. 2015;37(2):94-9.

17. Cella D, Choi SW, Condon DM, Schalet B, Hays RD, Rothrock NE, et al. PROMIS ${ }^{\circledR}$ adult health profiles: efficient short-form measures of seven health domains. Value Health. 2019;22(5):537-44.

18. Cook KF, Jensen SE, Schalet BD, Beaumont JL, Amtmann D, Czajkowski $\mathrm{S}$, et al. PROMIS measures of pain, fatigue, negative affect, physical function, and social function demonstrated clinical validity across a range of chronic conditions. J Clin Epidemiol. 2016;73:89-102.

19. Hahn EA, DeVellis RF, Bode RK, Garcia SF, Castel LD, Eisen SV, et al. Measuring social health in the patient-reported outcomes measurement information system (PROMIS): item bank development and testing. Qual Life Res. 2010;19(7):1035-44.

20. Ng R, Lee CF, Wong NS, Luo N, Yap YS, Lo SK, et al. Measurement properties of the English and Chinese versions of the functional assessment of cancer therapy-breast (FACT-B) in Asian breast cancer patients. Breast Cancer Res Treat. 2011;131(2):619-25.

21. Bella OD, Cocchiara RA, Luca AD, Frusone F, Aceti V, Sestili C, et al. Functional assessment of cancer therapy questionnaire for breast cancer (FACT-B): Italian version validation. Clin Ter. 2018;169(4):e151-4.

22. Pandey M, Thomas BC, Ramdas K, Eremenco S, Nair MK. Quality of life in breast cancer patients: validation of a FACT-B Malayalam version. Qual Life Res. 2002;11:87-90.

23. Algamdi MM, Hanneman SK. Psychometric performance of the Arabic versions of the cancer behavior inventory-brief and the functional assessment of cancer therapy-breast. Cancer Nurs. 2019;42(2):129-38.

24. Wan C, Zhang D, Yang Z, Tu X, Tang W, Feng C, et al. Validation of the simplified Chinese version of the FACT-B for measuring quality of life for patients with breast cancer. Breast Cancer Res Treat. 2007;106(3):413-8.

25. Yang Q, Yu XX, Zhang W, Li H. Mapping function from FACT-B to EQ-5D-5 $\mathrm{L}$ using multiple modelling approaches: data from breast cancer patients in China. Health Qual Life Out. 2019;17:153.

26. Hahn EA, Cella D, Bode RK, Hanrahan RT. Measuring social well-being in people with chronic illness. Soc Indic Res. 2010;96:381-401.

27. Hahn EA, DeWalt DA, Bode RK, Garcia SF, DeVellis RF, Correia H, et al. New English and Spanish social health measures will facilitate evaluating health determinants. Health Psychol. 2014;33:490-9.

28. Cai TT, Huang QM, Wu FL, Huang YS, Yang Y, Zhu R, et al. Latent class analysis of social function of breast cancer patients receiving chemotherapy based on patient-reported outcomes. J Nurs Train. 2020;45(5):S3-11.

29. Schalet BD, Pilkonis PA, Yu L, Dodds N, Johnston KL, Yount S, et al. Clinical validity of PROMIS depression, anxiety, and anger across diverse clinical samples. J Clin Epidemiol. 2016;73:119-27.

30. Terwee CB, Bot SDM, de Boer MR, van der Windt DAWM, Knol DL, Dekker $J$, et al. Quality criteria were proposed for measurement properties of health status questionnaires. J Clin Epidemiol. 2007;60(1):34-42.

31. Brown TA. Confirmatory factor analysis for applied research. 2 nd ed. New York: Guilford Press; 2015

32. Hu LT, Bentler PM. Cutoff criteria for fit indexes in covariance structure analysis: conventional criteria versus new alternatives. Struct Equ Model. 1999;6:1-55.

33. Carle AC, Riley W, Hays RD, Cella D. Confirmatory factor analysis of the patient reported outcomes measurement information system (PROMIS) adult domain framework using item response theory scores. Med Care. 2015;53(10):894-900.

34. Tamminga SJ, de Boer AG, Verbeek JH, Frings-Dresen MHW. Breast cancer survivors' views of factors that influence the return-to-work process-a qualitative study. Scand J Work Environ Health. 2012;38(2):144-54.

35. Paalman $\mathrm{CH}$, van Leeuwen FE, Aaronson NK, de Boer AGEM. Employment and social benefits up to 10 years after breast cancer diagnosis: a population-based study. Br J Cancer. 2016;114(1):81-7. 
36. Crins MHP, Terwee CB, Ogreden O, Schuller W, Dekker P, Flens G, et al. Differential item functioning of the PROMIS physical function, pain interference, and pain behavior item banks across patients with different musculoskeletal disorders and persons from the general population. Qual Life Res. 2019;28(5):1231-43.

37. Mukaka MM. Statistics corner: a guide to appropriate use of correlation coefficient in medical research. Malawi Med J. 2012;24(3):69-71.

38. Castro-Rodrigues P, Camacho M, Almeida S, Marinho M, Soares C, Barahona-Corrêa JB, et al. Criterion validity of the Yale-Brown ObsessiveCompulsive Scale second edition for diagnosis of obsessive-compulsive disorder in adults. Front Psychiatry. 2018;9:431

39. Cox ED, Connolly JR, Palta M, Rajamanickam VP, Flynn KE. Reliability and validity of PROMIS ${ }^{\circledR}$ pediatric family relationships short form in children 8-17 years of age with chronic disease. Qual Life Res. 2019;29(1):191-9.

40. Peeters MJ, Harpe SE. Updating conceptions of validity and reliability. Res Soc Admin Pharm. 2020;16(8):1127-30.

41. Carlozzi NE, lanni PA, Lange RT, Brickell TA, Kallen MA, Hahn EA, et al. Understanding health-related quality of life of caregivers of civilians and service members/veterans with traumatic brain injury: establishing the reliability and validity of PROMIS social health measures. Arch Phys Med Rehab. 2018;100(4Suppl):S110-8.

42. Paalman $\mathrm{CH}$, van Leeuwen FE, Aaronson NK, de Boer AGEM, van de PollFranse L, Oldenburg HSA, et al. Employment and social benefits up to 10 years after breast cancer diagnosis: a population-based study. $\mathrm{Br} J$ Cancer. 2016;114(1):81-7.

43. Olsson M, Nilsson M, Fugl-Meyer K, Petersson LM, Wennman-Larsen A, Kjeldgård $L$, et al. Life satisfaction of women of working age shortly after breast cancer surgery. Qual Life Res. 2017:26(3):673-84.

44. Vayr F, Montastruc M, Savall F, Despas F, Judic E, Basso M, et al. Work adjustments and employment among breast cancer survivors: a French prospective study. Support Care Cancer. 2020;28:185-92.

45. Zhang SW, Suna K, Zheng RS, Zeng HM, Zhang SW, Xia CF, et al. Cancer incidence and mortality in China, 2015. J Natl Cancer Center. 2021;21:22.

\section{Publisher's Note}

Springer Nature remains neutral with regard to jurisdictional claims in published maps and institutional affiliations.
Ready to submit your research? Choose BMC and benefit from:

- fast, convenient online submission

- thorough peer review by experienced researchers in your field

- rapid publication on acceptance

- support for research data, including large and complex data types

- gold Open Access which fosters wider collaboration and increased citations

- maximum visibility for your research: over $100 \mathrm{M}$ website views per year

At BMC, research is always in progress.

Learn more biomedcentral.com/submissions 